\title{
Inter-Tracheid and Cross-Field Pitting in Compression Wood and Opposite Wood of Norway Spruce (Picea abies L.)
}

\author{
AsgharTARMIAN, Mohammad AZADFALLAH, Hadi GHOLAMIYAN, MahdiSHAHVERDI \\ University of Tehran, Faculty of Natural Resources, Department of Wood and Paper Science and Technology, Karaj, Iran; tarmian@ut.ac.ir
}

\begin{abstract}
Inter-tracheid and cross-filed pit specifications in compression wood and opposite wood of Norway spruce (Picea abies) were determined. Fewer pits of a smaller size and a smaller aperture diameter were observed in compression wood. In contrast to the uniseriate arrangement of bordered pit pairs in compression wood, both uniseriate and biseriate pits were observed in opposite wood. In contrast to the circular view of the pit aperture in opposite wood, a slit-like pit aperture was often observed in compression wood. SEM images showed a number of helical fissures on the tracheid walls and bordered pits of compression wood along the microfibril angle in the $S_{2}$ layer. The cross-field pits in compression wood were dominantly piceoid but sometimes cupressoid and occasionally taxodioid, whereas they were mostly piceoid and occasionally cupressoid in opposite wood. Overall, some significant differences in the inter-tracheid and cross-field pitting between the compression wood and opposite wood can give some explanations for their different air permeability and drying kinetics found in the previous studies.
\end{abstract}

Keywords: compression wood, cross-field pit, inter-tracheid pit, Norway spruce (Picea abies), opposite wood

\section{Introduction}

Small openings or recesses in the secondary cell wall known as pits are among the important wood microscopic characteristics of tracheids in softwoods. They are key features to identify a wood species, and their type, appearance, size, and frequency can be different among wood species. Various kinds of pitting occur in softwoods, but inter-tracheid bordered pit pairs occupy a higher fraction of the conifer pit volume and also play an important role for the passage of fluids through wood and thus its permeability. Different types of pitting, such as the pits between two ray tracheids, the pits between a ray tracheid and a longitudinal tracheid, etc have been comprehensively studied in Pinus banksiana by Yang and Benson (1997). They indicated a significant variation in the size and structure of the pit pairs, occurring between the different wood cells. The wood permeability is affected by the size, frequency, and structure of pit pairs and it may be decreased as a result of pit aspiration, pit occlusion or pit incrustation (Siau, 1984). Usta and Mike (2003) evaluated the permeability of cross-field pits in uniseriate rays of Sitka spruce. They concluded that one of the important anatomical features influencing preservative uptake is the size and number of the cross-field pits. This is why the pit specification (the overall pit diameter, the pit membrane thickness, the pit aperture or torus size, the pit aperture shape, etc.) and its arrangement and proportion are of concern in drying (Usta and Hale, 2006; Gerards et al., 2007), modification (Boonstra et al., 2006), and impregnation of wood (Olsson et al., 2001; Watanabe et al., 1998). Also, the structure of bordered pits is important for the tree's hydraulic function (Pittermann et al., 2006; Hacke et al., 2004; Valli et al., 2002). In addition to the importance of the bordered pits on the radial side of longitudinal tracheids, the halfbordered pitting between the longitudinal tracheids and rays, called cross-field pits can be an important diagnostic feature for wood identification (Gerards et al., 2007). Furthermore, it is a key feature because of its contribution to the radial flow of fluids or moisture through wood (Siau, 1984; Usta and Hale, 2003).

Despite a lot of research conducted for the study on the coniferous pitting (Sachs, 1963; Comstock and Cote, 1968; Petty, 1972; Barnett and Harris, 1975; Timell, 1986; Yang and Benson, 1997; Sirvio and Karenlampi, 1998; Pitterman et al., 2005; Usta and Hale, 2006), there has been a lack of precise information concerning the pit structure in compression wood, a type of reaction wood in conifers. Compression wood is a gravitational response (Burgert et al., 2004) that is usually formed on the lower side of a leaning tree or the underside of branches (Timell, 1986) but also sometimes in all areas of an apparently vertical tree (Warensjo, 2003; Donaldson et al., 2004). The abnormal properties of compression wood make it an undesirable feature for lumbering (Timell, 1986), wood-based panels (Akbulut et al., 2006), wood drying (Warensjö, 2003; Tarmian et al., 2008), and pulp and paper manufacture (Ban et al., 2004). Thus, its anatomical structure has been largely investigated (Timell, 1986; Yoshizawa and Idei, 1987; Singh and Donaldson, 1999; Ohman, 2001; Donaldson et al., 2004; Burgert et al., 2004). Thanks to the research, interesting and useful information has been 
146

obtained for the compression wood structure, reflecting its abnormal behavior. Regarding compression wood pitting, smaller and fewer bordered pits have been reported in the compression wood of Picea abies (Mayr et al., 2005), Pinus radiata (Davis et al., 2002), and Pinus banksiana lamb (Yang and Benson, 1997) when compared to the normal wood. Timell (1986) found that bordered pits in compression wood tracheids of Ginkgo biloba lack torus features; however, Yang and Benson (1997) observed a thin torus in compression wood of Pinus banksiana lamb. The present study attempts to precisely investigate the inter-tracheid and cross-field pitting in compression wood of Norway spruce (Picea abies) compared to its corresponding opposite wood to well understand if the special pitting in compression wood can be a main responsible for its undesirable drying and impregnation properties.

\section{Materials and methods}

\section{Tree selection and wood sampling}

The tree selected for the study was from the Kheirood Kenar forest in the north of Iran. From a growth site of a severe slope, a young Norway spruce (Picea abies) leaning tree with approximately 15 years of growth was felled in the spring. In fact, the specimens that were prepared for the study were juvenile wood of the species. Then, 5 allsapwood discs containing large amounts of severe compression wood were chosen from diameter breast height of the tree. Subsequently, 30 small clear samples were taken from the discs in the compression and opposite wood areas $(6$ samples from each disc; 3 compression wood samples and 3 opposite wood samples). The compression and opposite wood samples were prepared from similar growth rings. A schematic sample preparation is shown in Fig. 1.

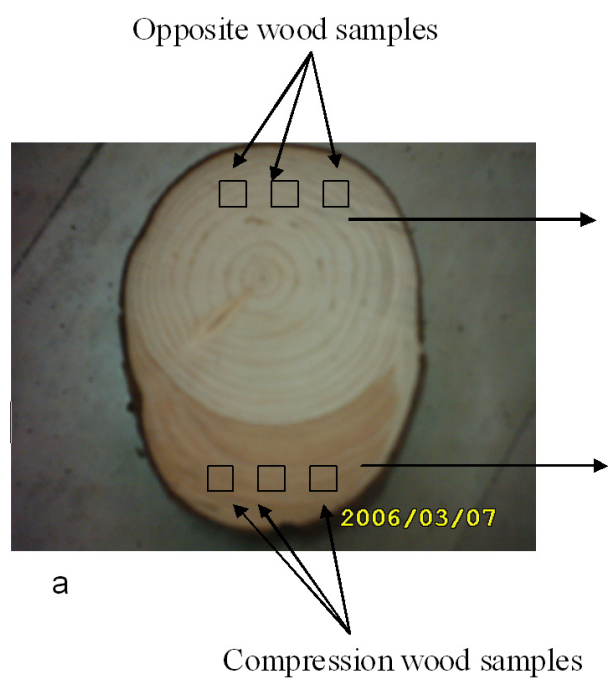

Compression wood samples
The validity of severe compression wood sampling was confirmed by the observation of a rounded appearance of thick walled tracheids under a light microscope (Fig. 1c). Since a mild compression wood, which macroscopically resembles normal wood (Donaldson et al., 2004), may develop in opposite wood zones, the accuracy of the opposite wood sampling was also evaluated using a light microscope (Fig. 1b). The discs containing the mild compression wood in the opposite wood zone were discarded.

\section{Inter-tracheid and cross-field pitting studies}

The specifications of inter-tracheid and cross-filed pitting were examined in compression and opposite wood. Four techniques were employed for the measurements.

\section{Light microscopy (LM) studies}

A light microscope (LM) was used to measure the features of bordered pits on the radial side of longitudinal tracheids, including the overall diameter, arrangement and frequency of the pits in tracheid overlap area per $\mathrm{mm}^{2}$. For the measurements, the radial and tangential sections of 20 to $30 \mu \mathrm{m}$ thickness were prepared using a sliding microtome, and the sections were then examined without any staining treatment.

\section{Environmental Scanning Electron Microscopy (ESEM) studies}

The environmental scanning electron microscopy (ESEM) studies were conducted to evaluate the pit structure in green condition and to avoid the drying effect on the pit shape. Thus, green wood samples were prepared for ESEM studies.
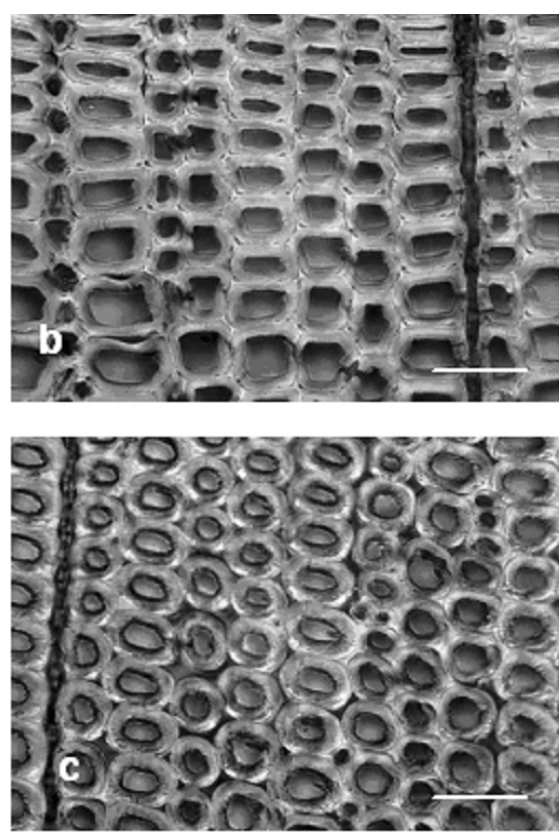

Fig. 1. a: A Norway spruce (Picea abies) disc containing severe compression wood; b: A cross section view of opposite wood taken from latewood; c: A cross section image of compression wood. Note the severe compression wood with thick-walled tracheids of rounded shapes and intercellular spaces between them. Scale bars $=50 \mu \mathrm{m}$ 
Scanning Electron Microscopy (SEM) studies

In contrast to ESEM studies, the scanning electron microscope (SEM) technique was applied to examine the effect of drying on the pit structure, particularly on the development of helical drying fissures in compression wood. The SEM technique was also used to measure the crossfield pit specifications. The type, size, and number of the pits per cross field were studied in each wood. The size of pit aperture for each wood was also determined.

\section{Wood maceration and fiber isolation studies}

The Franklin method (FM) was applied for wood maceration and fiber isolation and to know if the high lignification of compression wood tracheids with a large $\mathrm{S}_{2}$ microfibril angle (MFA) can affect the pit studies by this method. Six compression and opposite wood blocks were split into small pieces of matchstick size and were macerated by using 50-50 V/V mixture of $60 \%$ acetic acid and 30\% hydrogen peroxide. After staining with safranin, the fiber bundles were separated by shaking, and the pits of isolated tracheids were measured under a light microscope.

\section{Statistical analysis}

The mean of 50 measurements was taken in each character per wood sample. The value reported for all features of opposite wood was an average of early- and latewood of three annual rings, and the one reported for those of compression wood was an average of the severe compression wood within the corresponding growth rings. The statistical analysis was conducted using SPSS software. Duncan's Test was applied to statically compare the mean values.

\section{Results and discussion}

\section{Light microscopy (LM) studies}

The inter-tracheid and cross-field pit specifications are summarized in Tab. 1 . The results showed that the compression wood has a smaller pit diameter and pit aperture than the opposite wood, (see also Fig. 2). A major difference between the size of inter-tracheid pitting in compression and normal wood can be better understood by the observation of Fig. $2 \mathrm{~d}$, where the earlywood of the normal wood is beside the compression wood. In addition, the results revealed that fewer inter-tracheid pits occurred in compression wood (Tab. 1 and Figs. 2a and b). Our findings are in agreement with the results reported for compression woods of Picea abies (Mayr et al., 2005), Pinus radiata (Davis et al., 2002), and Pinus banksiana lamb (Yang and Benson, 1997). Whether in compression or opposite wood, most of the pits were concentrated in the long tapered ends of longitudinal tracheids; i.e., in the tracheids' overlap area. Only uniseriate arrangement of bordered pits occurred on the radial walls of compression wood tracheids, whereas normally uniseriate and rarely biseriate pits were observed in opposite wood. The biseriate pits in opposite wood were arranged either alternately or
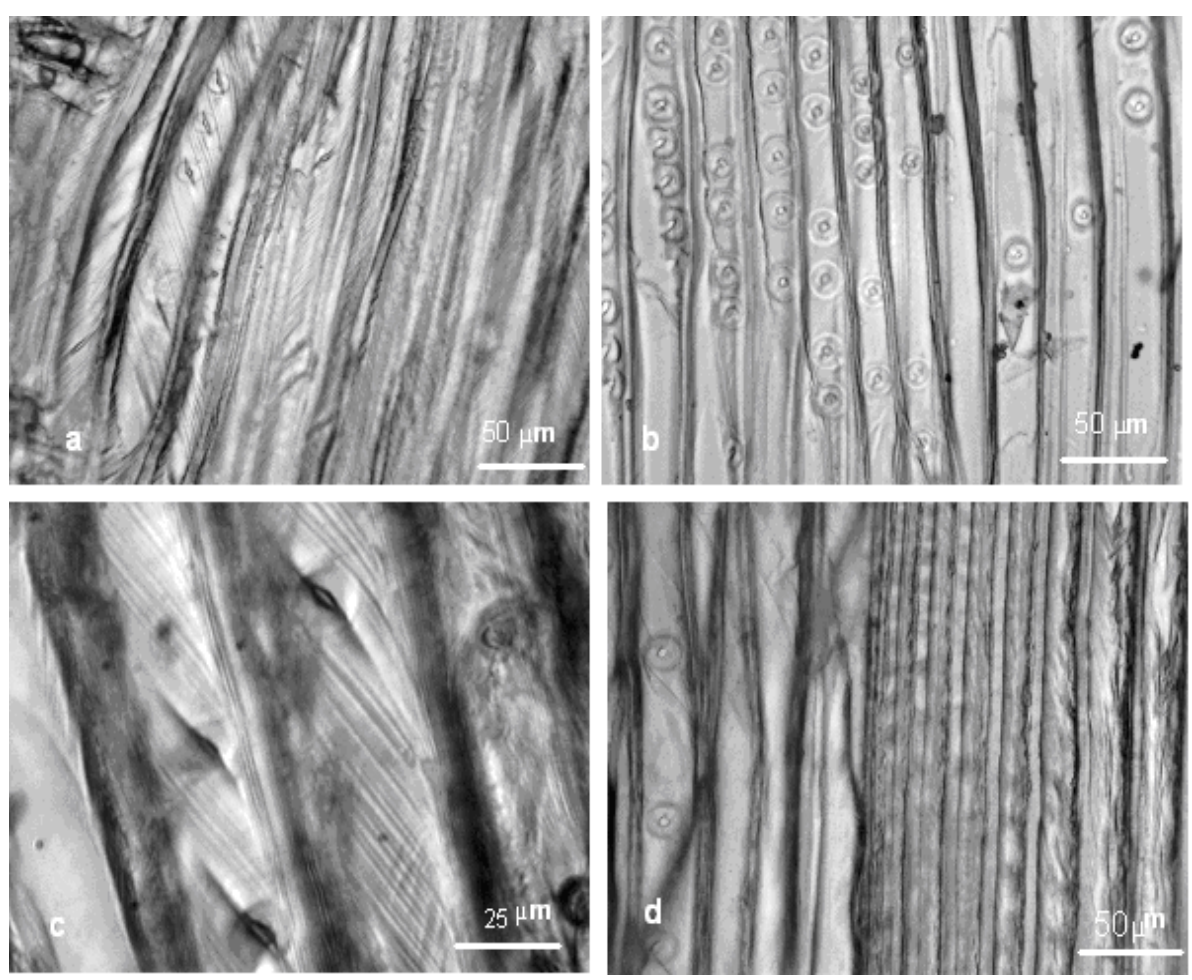

Fig. 2. Light microscope images of bordered pits in compression and opposite wood of Picea abies. Scarce and small bordered pits in compression wood (a) vs. larger and more numerous pits in opposite wood (b), Slit-like pit apertures of bordered pits in compression wood (c); Compression wood tracheids beside normal wood ones in earlywood (d). Note that the bordered pits are obvious in normal wood but unclear in compression wood 
148

Tab. 1. Inter-tracheid and cross field pit specifications of spruce compression and opposite wood

\begin{tabular}{ccccc}
\hline Wood type & $\begin{array}{c}\text { Pit } \\
\text { diameter } \\
(\mu \mathrm{m})\end{array}$ & $\begin{array}{c}\text { Pit } \\
\text { aperture } \\
\text { diameter } \\
(\mu \mathrm{m})\end{array}$ & $\begin{array}{c}\text { Pit number in } \\
\text { inter-tracheid } \\
\text { overlap area } \\
\left(\mathrm{n} / \mathrm{mm}^{2}\right)\end{array}$ & $\begin{array}{c}\text { Cross- } \\
\text { field pit } \\
\text { number } \\
\left(\mathrm{n} / \mathrm{mm}^{2}\right)\end{array}$ \\
\hline $\begin{array}{c}\text { Compression } \\
\text { wood }\end{array}$ & $\begin{array}{c}8.1 \\
(2.13) \mathrm{a}^{1}\end{array}$ & $\begin{array}{c}\mathrm{m}^{1} \\
(0.52) \mathrm{a}\end{array}$ & $\begin{array}{c}10.7 \\
(3.75) \mathrm{a}\end{array}$ & $\begin{array}{c}1.9 \\
(1-2) \mathrm{a}\end{array}$ \\
$\begin{array}{c}\text { Opposite } \\
\text { wood }\end{array}$ & 10.5 & 3.1 & 16.4 & 2.4 \\
$(1.43) \mathrm{b}^{2}$ & $(0.52) \mathrm{b}$ & $(4.85) \mathrm{b}$ & $(1-4) \mathrm{b}$ \\
\hline
\end{tabular}

* Standard deviation; 1 and 2 Duncan test results

oppositely. Under the light microscope, the bordered pits of compression wood appeared to be crossed diagonally by a slit (Figs. $2 \mathrm{a}$ and c). As can be seen from Fig. 2 c, the slope of slits is along the microfibril angle in the $S_{2}$ layer.

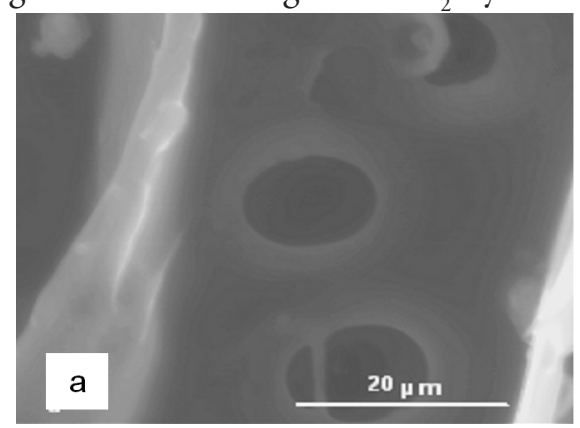

Fig. 3. ESEM micrographs of bordered pits in opposite and compression wood of Picea abies; a: Bordered pits on radial side of opposite wood tracheids; b: Bordered pits with slit-like apertures in compression wood
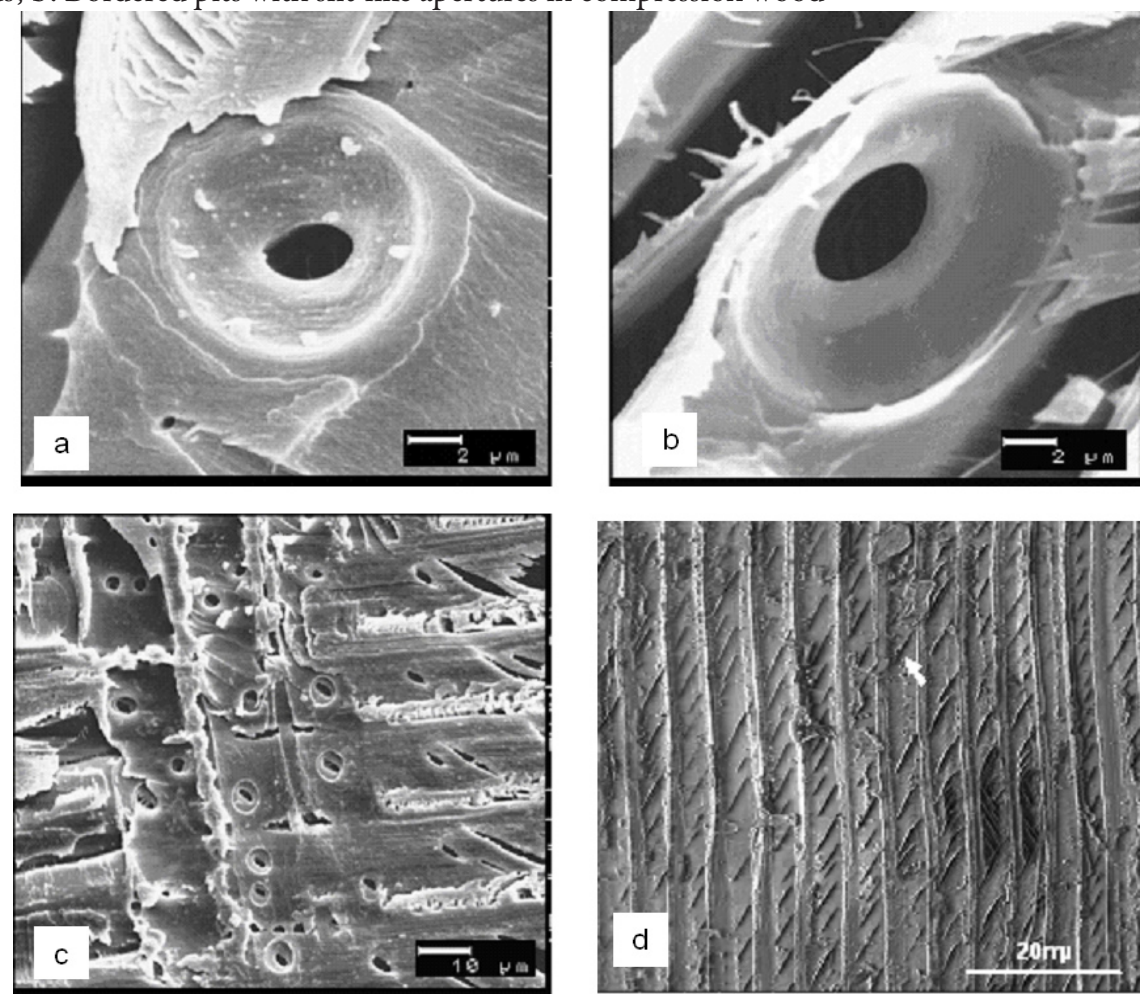

Fig. 4. SEM micrographs of bordered pits on radial side of longitudinal tracheids in compression and opposite wood of Picea abies. A small bordered pit in compression wood (a) vs. a larger one in opposite wood (b). Non-contacting bordered pits with slit-like apertures in compression wood (c). Helical fissures on the radial side of longitudinal tracheids in compression wood (d) 

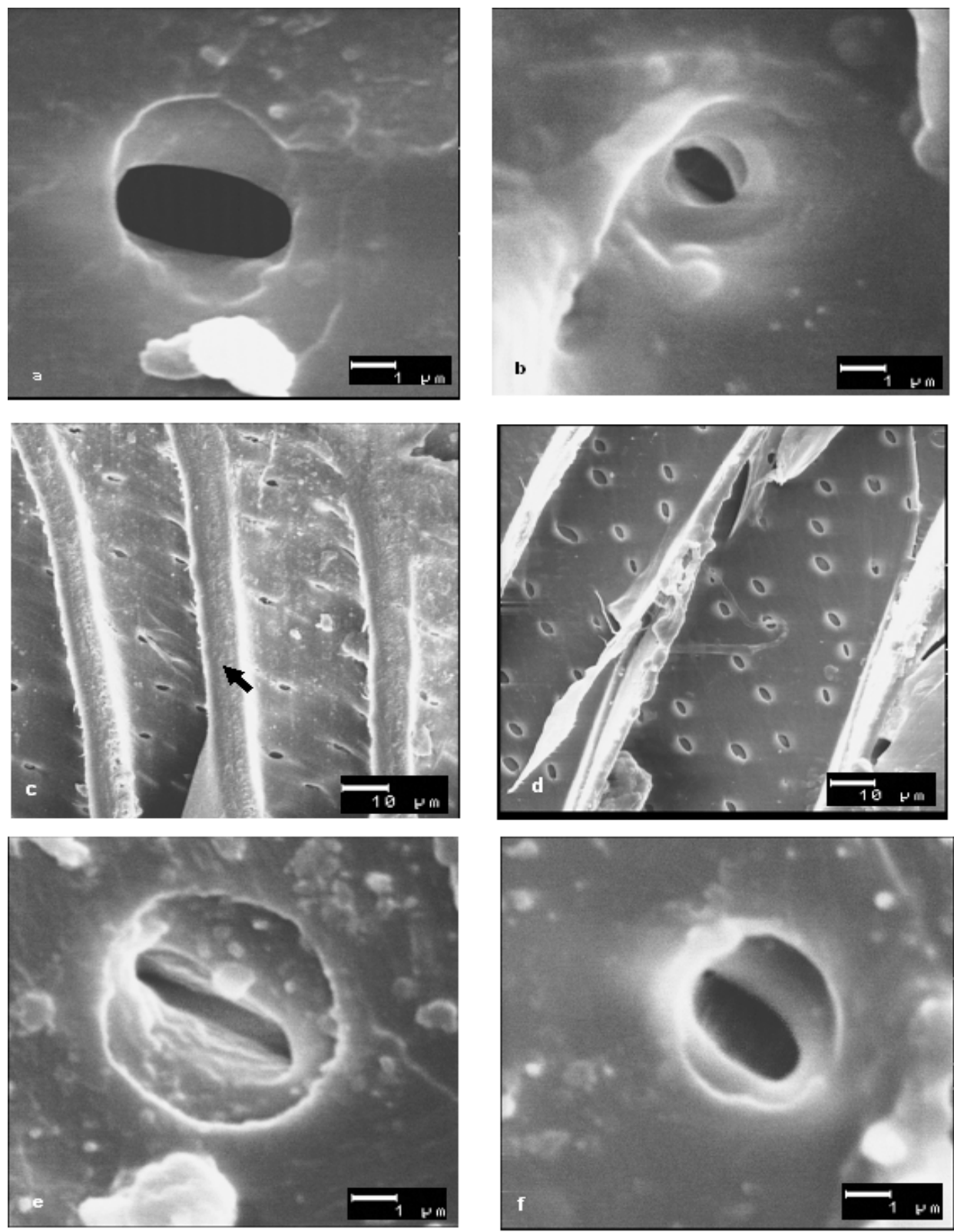

Fig. 5. SEM micrographs of cross-field pits in compression and opposite wood of Picea abies; a: A cupressoid cross-field pit in opposite wood; b: A small taxodioid cross-filed pit in compression wood; c: Tracheid pit apertures in compression wood; d: Larger apertures of tracheid pits in opposite wood; e: A piceoid cross-field pit in compression wood; f: A cupressoid cross-field pit in compression wood

pits (Fig. $4 \mathrm{f}$ ). This is in agreement with that reported by Timell (1986).

Like inter-tracheid pitting, a pronounced variation was observed in cross-field pitting between the compression and opposite wood of Picea abies (Fig. 5). Pits that occurred in cross fields of compression wood were typically piceoid but sometimes cupressoid and occasionally taxodioid, whereas those in cross fields of opposite wood were mostly piceoid and occasionally cupressoid. As can be seen from Figs. $5 \mathrm{c}$ and d, a smaller aperture occurred in ray cross-field pits of compression wood and fewer crossfield pits were also observed in compression wood (Tab. 1). In opposite wood, the pits of cross fields were arranged alternately.

\section{Wood maceration and fiber isolation studies}

Figure 6 shows some isolated tracheids of compression and opposite wood, made by Franklin method. Under a light microscope, the bordered pits were obvious on the opposite wood tracheids (Figs. $6 \mathrm{c}$ and d) but unclear on the compression wood ones (Figs. $6 \mathrm{a}$ and b). Thus, the method was found to be unsuccessful for the measuring of the bordered pit size in compression wood. This may be due to a high lignification of compression wood tracheids with a large $S_{2}$ microfibril angle (MFA). 

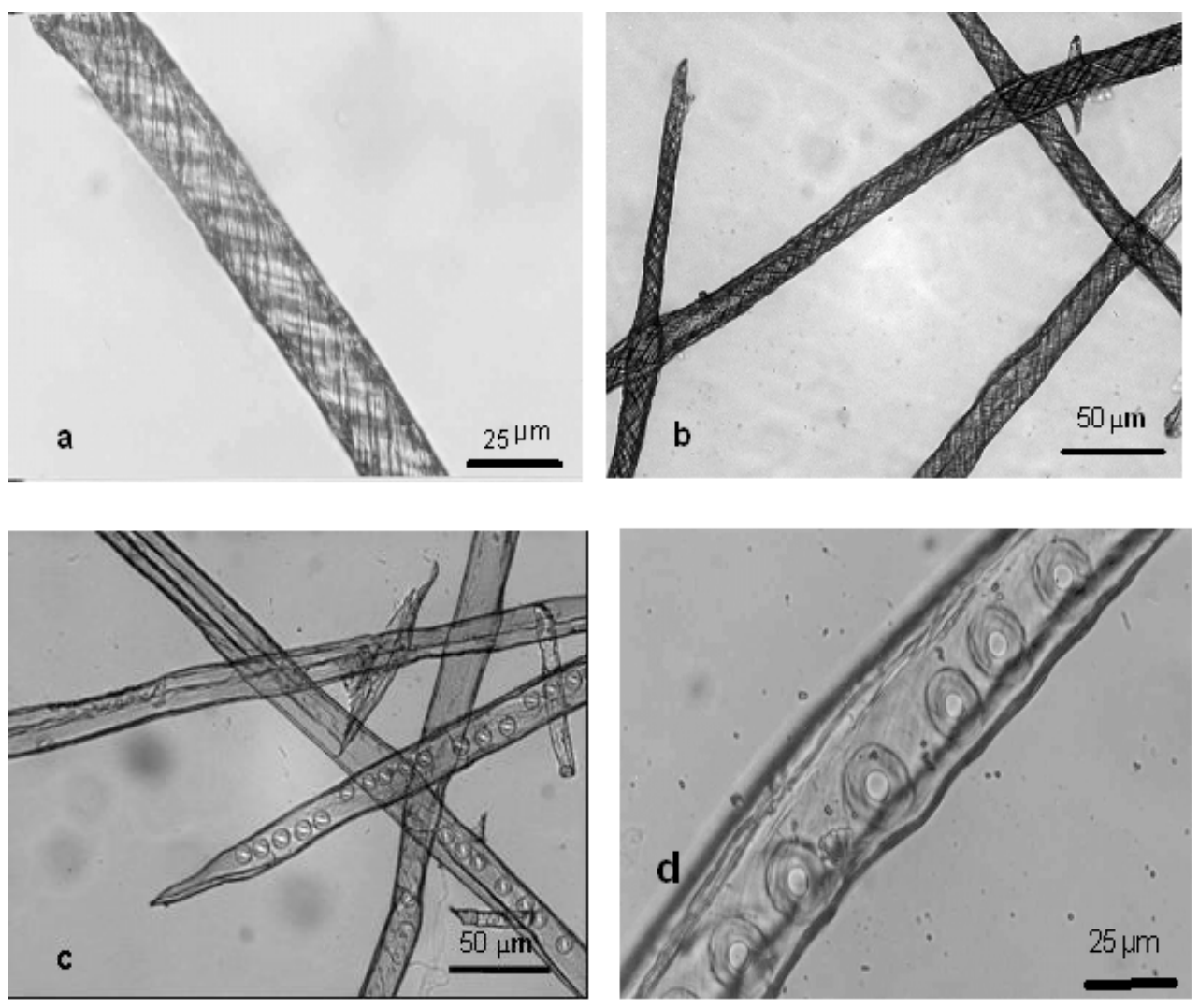

Fig. 6. Light microscope images of macerated longitudinal tracheids from compression wood (a and b) and opposite wood (c and d) of Picea abies. Bordered pits on the compression wood tracheids are unclear

\section{Conclusions}

On the whole, a major difference was observed in size, appearance, and frequency of inter-tracheid and crossfield pits between compression and opposite wood of Picea abies. In compression wood, both types of the pits had a smaller total diameter and a smaller aperture than in opposite wood. Pit frequency $\left(\mathrm{n} / \mathrm{mm}^{2}\right)$ of radial tracheid walls and pit number per cross field were lower in compression wood. In contrast to circular view of pit aperture in opposite wood, a slit-like aperture was often observed in compression wood. Uniseriate arrangement of bordered pits occurred in compression wood, whereas biseriate pits were also observed in opposite wood. Typically piceoid, sometimes cupressoid, and occasionally taxodioid crossfield pitting occurred in compression wood. In contrast, cross-field pitting in opposite wood was mostly piceoid and occasionally cupressoid. Wood maceration and fiber isolation using Franklin method was found to be unsuccessful to determine the intertracheid bordered pit specifications of compression wood, probably because of high lignification of compression wood tracheids with a large $S$ microfibril angle (MFA). In contrast to ESEM studies, the SEM studies revealed a number of helical fissures on the compression wood tracheid walls, probably due to the drying process applied during the SEM sample preparation. Overall, it can be concluded that the different inter- tracheid and cross-field pitting in the spruce compression wood and opposite wood can be responsible for the different air permeability and drying kinetics between the spruce compression wood and opposite wood found in the previous studies (Tarmian and Perre, 2009; Tarmian et al., 2009).

\section{Acknowledgments}

One of the authors, Asghar Tarmian, wishes to acknowledge Professor Patrick Perré (LERMAB-Wood Science Laboratory, ENGREF, Nancy, France) for his kind help for the measurements of bordered pit specifications by ESEM in his laboratory.

\section{References}

Akbulut A, Nadir A (2006). Effect of compression wood on surface roughness and surface absorption of medium density fiberboard. Silva Fennica 40:161-167.

Ban W, Mancoski D, Lucia LA (2004). Evaluation of the pulping response of juvenile and mature black spruce compression wood. Cellulose Chemistry and Technology 38:79-85.

Barnett JR, Harris JM (1975). Early stages of bordered pit formation in radiata pine. Wood Science and Technology 9:233-241.

Boonstra MJ, Rijsdijk JF, Sander C, Kegel E, Tjeerdsma B, 
Militz H, Vanacker J, Stevens M (2006). Microstructural and physical aspects of heat treated wood, Part 1: Softwoods. Maderas. Ciencia y Tecnología 8:193-208.

Burgert I, Fruhmann K, Keckes J, Fratzl P, Tschegg SS (2004). Structure-function relationships of four compression wood types: Micromechanical properties at the tissue and fiber level. Trees 18:480-485.

Comstock GL, Coté WA (1968). Factors affecting permeability and pit aspiration. Wood Sci Technol 2:279-291.

Davis CP, Carrington CG, and Sun ZF (2002). The influence of compression wood on the drying curves of Pinus radiata in dehumifier conditions. Drying Technology 20:2005-2026.

Donaldson LA, Grace J, Downes GM (2004). Within-tree variation in anatomical properties of compression wood in radiata pine. IAWA J 25:253-271.

Gerards T, Damblon F, Wauthoz B, Gerrienne P (2007). Comparison of cross-field pitting in fresh, dried and charcoalified. IAWA J 28:49-60.

Hacke UG, Sperry JS, Pittermann J (2004). Analysis of circular bordered pit function. II. Gymnosperm tracheids with torus-margo pit membranes. American Journal of Botany 91:386-400.

Mayr S, Bardage S, Brandström J (2005). Hydraulic and anatomical properties of light bands in Norway spruce compression wood. Tree Physiology 26:17-35.

Öhman M (2001). The measurement of compression wood and other wood features and the prediction of their impact on wood products. Lulea University of Technology, Division of Wood Technology, PhD Diss.

Olsson T, Megnis M, Varna J, Lindberg H (2001). Study of the transverse liquid flow paths in pine and spruce using scanning electron microscopy. Journal of Wood Science 47:282-288.

Petty JA (1972). The aspiration of bordered pits in conifer wood. Proc R Soc Lond B Biol Sci 181:395-406.

Pittermann JA, Sperry JS, Hacke UG, Wheeler JK, Sikkema EH (2006). Inter-tracheid pitting and the hydraulic efficiency of conifer wood: The role of tracheid allometry and cavitation protection. American Journal of Botany 93:1265-1273.

Sachs IB (1963). Torus of the bordered pit membrane in conifers. Nature 198:906-907.
Siau JF (1984). Transport Processes in Wood. Springer, Berlin, Heidelberg.

Singh AP, Donaldson LA (1999). Ultrastructure of tracheid cell walls in radiata pine (Pinus radiata) mild compression wood. Can J Bot 77:32-40.

Sirvio J, Kärenlampi P (1998). Pits as natural irregularities in softwood fibers. Wood and Fiber Science 30:27-39.

Tarmian A, Perre P (2009). Air permeability in longitudinal and radial directions of compression wood of Picea abies $\mathrm{L}$. and tension wood of Fagus sylvatica, Holzforschung 63:352356.

Tarmian A, Remond R, Faezipour M, Karimi A, Perré P (2008). Reaction wood drying kinetics: Tension wood in Fagus sylvatica and compression wood in Picea abies. Wood Science and Technology 43:113-130.

Timell TE (1986). Compression Wood in Gymnosperms. Vol. 3, Springer-Verlag, Heidelberg, Germany.

Usta I, Hale MD (2003). Radial permeability of Sitka spruce as affected by wood structure. IAWA Journal 24:197-204.

Usta I, Hale MD (2006). Comparison of the bordered pits of two species of spruce (Pinaceae) in a green and kiln-dried condition and their effects on fluid flow in the stem wood in relation to wood preservation. Forestry 79:467-475.

Valli A, Koponen A, Vesala T, Timonen J (2002). Simulation of water flow through bordered pits of conifer xylem. Journal of Statistical Physics 107:121-142.

Warensjö M (2003). Compression wood in Scots pine and Norway spruce-Distribution in relation to external geometry and the impact on the dimensional stability in sawn wood. Swedish University of Agricultural Science, Department of Forest Products and Markets, PhD Diss.

Watanabe U, Imamura Y, Iida I (1998). Liquid penetration of precompressed wood. VI. Anatomical characterization of pit fractures. Journal of Wood Science 44:158-162.

Yang KC, Benson C (1997). Ultrastructure of pits in pinus banksiana Lamb. Wood Science and Technology 31:153169.

Yoshizawa N, Idei T (1987). Some structural and evolutionary aspects of compression wood tracheids. Wood and Fiber Science 19:343-352. 